\title{
Estrogenic activities of diuron metabolites in female Nile tilapia (Oreochromis niloticus)
}

\author{
Thiago Scremin Boscolo Pereira a , Camila Nomura Pereira Boscolo a \\ Andreia Arantes Felício ${ }^{\mathrm{b}}$, Sergio Ricardo Batlouni ${ }^{\mathrm{c}}$, Daniel Schlenk ${ }^{\mathrm{d}}$, \\ Eduardo Alves de Almeida ${ }^{\text {b, * }}$ \\ a Department of Zoology and Botany, Universidade Estadual Paulista (IBILCE/UNESP), Rua Cristóvão Colombo, 2265, CEP - 15054-000, São José do Rio Preto, \\ SP, Brazil \\ ${ }^{\mathrm{b}}$ Department of Chemistry and Environmental Sciences, Universidade Estadual Paulista (IBILCE/UNESP), Rua Cristóvão Colombo, 2265, CEP - 15054-000, \\ São José do Rio Preto, SP, Brazil \\ ${ }^{c}$ Aquaculture Center, Universidade Estadual Paulista (CAUNESP), Via de Acesso Prof. Paulo Donato Castelane, s/n., CEP - 14884-900, Jaboticabal, SP, Brazil \\ d Department of Environmental Sciences, University of California, Riverside, 3401Watkins Dr, Riverside, CA 92521, USA
}

\section{H I G H L I G H T S}

- Nile tilapia were exposed for 25 days to $100 \mathrm{ng} / \mathrm{L}$ diuron and three diuron metabolites.

- Diuron metabolites increased $\mathrm{E}_{2}$ plasma levels, gonadosomatic indices and vitellogenic oocytes.

- Diuron and its metabolites caused a decrease in germinative cells.

- Concentrations of $17 \alpha$-hydroxyprogesterone (17 $\alpha$-OHP) was not altered.

\section{A R T I C L E I N F O}

\section{Article history:}

Received 22 October 2015

Received in revised form

18 December 2015

Accepted 19 December 2015

Available online 30 December 2015

Handling Editor: Jim Lazorchak

\section{Keywords:}

Nile tilapia

Diuron

Diuron metabolites

Gametogenesis

Endocrine disrupting chemicals

\begin{abstract}
A B S T R A C T
Some endocrine disrupting chemicals (EDCs) can alter the estrogenic activities of the organism by directly interacting with estrogen receptors (ER) or indirectly through the hypothalamus-pituitarygonadal axis. Recent studies in male Nile tilapia (Oreochromis niloticus) indicated that diuron may have anti-androgenic activity augmented by biotransformation. In this study, the effects of diuron and three of its metabolites were evaluated in female tilapia. Sexually mature female fish were exposed for 25 days to diuron, as well as to its metabolites 3,4-dichloroaniline (DCA), 3,4-dichlorophenylurea (DCPU) and 3,4-dichlorophenyl- $N$-methylurea (DCPMU), at concentrations of $100 \mathrm{ng} / \mathrm{L}$. Diuron metabolites caused increases in $\mathrm{E}_{2}$ plasma levels, gonadosomatic indices and in the percentage of final vitellogenic oocytes. Moreover, diuron and its metabolites caused a decrease in germinative cells. Significant differences in plasma concentrations of the estrogen precursor and gonadal regulator17 $\alpha$-hydroxyprogesterone (17 $\alpha$-OHP) were not observed. These results show that diuron metabolites had estrogenic effects potentially mediated through enhanced estradiol biosynthesis and accelerated the ovarian development of $O$. niloticus females.
\end{abstract}

(c) 2015 Elsevier Ltd. All rights reserved.

\section{Introduction}

Endocrine disrupting chemicals (EDCs) are a class of environmental pollutants that can interfere with normal functions of the endocrine system (Tabb and Blumberg, 2006). Currently, the most

\footnotetext{
* Corresponding author.

E-mail address: ealmeida@ibilce.unesp.br (E. Alves de Almeida).
}

studied are those that alter estrogenic functions of the organism by interacting with estrogen receptors (ER) (Sumpter and Jobling, 1995; Schlenk et al., 2012; Forsgren et al., 2014; Kroon et al., 2014). The interaction of EDCs with the specific nuclear or membrane receptors in target cells may alter the function of the hypothalamic-pituitary-gonadal (HPG) axis affecting synthesis and clearance of key sex steroid hormones and be a potential mechanism of endocrine disruption (Kroon et al., 2014; Sun et al., 2014). The biosynthesis of sex steroid hormones also provides enzymatic 
targets for EDCs, especially the steps catalysed by cytochrome P450 aromatase (Sanderson and Van den Berg, 2003), the steroidogenic enzyme catalysing the final step in the conversion of androgens into estrogens (Simpson et al., 2002), which are important hormones involved in controlling the reproductive process in teleosts (Nagahama and Yamashita, 2008; Lubzens et al., 2010). In addition to $17 \beta$-estradiol, an additional steroid, $17 \alpha$-hydroxyprogesterone mediates oocyte growth and ovulation (Nagahama and Yamashita, 2008). Consequently, disruption in the biosynthesis of either compound could have impacts on reproductive function in females.

Diuron (3-(3,4-dichlorophenyl)-1,1-dimethylurea) is a substituted urea herbicide that has been identified in estrogenic fractions of water extracts (Schlenk et al., 2012) and caused indirect as well as sublethal effects on non-target species at environmentally relevant concentrations (Giacomazzi and Cochet, 2004; Cardone et al., 2008; Scheil et al., 2009). Following applications to soil, diuron has been shown to undergo run-off to rivers and lakes (Lamoree et al., 2002; Gooddy et al., 2002), potentially leading to negative effects to aquatic organisms such as teleosts (Nebeker and Schuytema, 1998; Mhadhbi and Beiras, 2012). Furthermore, diuron can also undergo biotransformation to 3,4-dichloroaniline (DCA), 3,4-dichlorophenylurea (DCPU) and 3,4-dichlorophenyl-N-methylurea (DCPMU) (Tixier et al., 2002; Hodge et al., 1967; Abbas et al., 2007). Some studies have shown that DCA may be more toxic than diuron (Giacomazzi and Cochet, 2004; Scheil et al., 2009; Da Rocha et al., 2013); however, studies regarding the toxicity of other metabolites (DCPMU, DCPU) are still limited. A recent study observed that diuron metabolites (mainly DCPMU, DCPU) have antiandrogenic activities in male Nile tilapia (Pereira et al., 2015), although no effect was observed for diuron, which is consistent with another recent study that did not observe estrogenic or antiandrogenic effects of diuron in juvenile barramundi (Lates calcarifer) (Kroon et al., 2015). Additional documented effects of diuron and its metabolites (DCA) in teleosts include morphological (Mhadhbi and Beiras, 2012; Gagnon and Rawson, 2009), biochemical (Sanchez-Muros et al., 2013), physiological (Vinggaard et al., 2000; Miranda et al., 2008; Scheil et al., 2009) and behavioral alterations (Saglio and Trijasse, 1998). However, studies evaluating potential steroidogenic activity associated with reproductive impacts of diuron and its metabolites are limited in teleosts.

Given the important role of sex steroid hormones in the regulation of reproduction in vertebrates and previous studies showing endocrine effects in male teleosts, the purpose of the present study was to evaluate the potential estrogenic effects of diuron and its metabolites on oogenesis of female Oreochromis niloticus. This work is the first to investigate these effects in teleost oogenesis providing useful data concerning the potential hazards of a widely used and frequently detected herbicide in the aquatic environment.

\section{Materials and methods}

\subsection{Ethical note}

This study was conducted in agreement with the precepts of National Council for the Control of Animal Experimentation (CONCEA) and was approved by the Committee for Ethics on Using Animal (CEUA), UNESP, São José do Rio Preto, SP, Brazil - permit $0715 / 2013$.

\subsection{Fish maintenance}

Sexually mature female 0 . niloticus in pre-ovulatory stage $(10.02 \pm 1.17 \mathrm{~cm}, 71.15 \pm 2.44 \mathrm{~g})$ were randomly selected from a stock culture maintained at the São Paulo State University (UNESP), São José do Rio Preto, Brazil. Fish were kept in 500 L indoor stock- tanks (ca. 1 fish/5 L) during 30 days for acclimation before experiment began. Food (commercial pellets for tropical fish, 32\% Crude Protein - Guabi-Pira/Brazil) was provided twice a day to satiation. External biological filters and constant aeration ensured water quality.

Water mean temperature was $26.6 \pm 1.1^{\circ} \mathrm{C}$ and photoperiod was 12L:12D (7:00-19:00 h). The water $\mathrm{pH}$ and $\mathrm{NH} 3$ levels during the exposure were $7.00 \pm 0.40$ and $0.55 \pm 0.08 \mathrm{mg}$, respectively. Fish were fed with ration for tropical fish (Guabi-Pira/Brazil) corresponding to $3 \%$ of biomass, provided twice a day (at 8:00 $\mathrm{h}$ and 18:00 h). Water containing the respective compounds was $100 \%$ replaced every five days by static renewal to ensure water quality and compound concentrations.

\subsection{Chemicals}

All chemicals used were of analytical grade and purchased from Sigma-Aldrich Chemical (St. Louis, MO, USA).

\subsection{Exposures}

After the acclimation period, the animals were exposed to diuron and its metabolites with subsequent measurements on oogenesis and plasma steroid levels. Six fish were used per treatment. Each fish was individually exposed in a glass aquarium of 17 L. One group remained in aquaria without contaminant (experimental controls) and the other groups were exposed to diuron, DCA, DCPU or DCPMU, at nominal concentrations of $100 \mathrm{ng} /$ $\mathrm{L}$ for 25 days. This concentration was selected based in a previous study that found diuron at concentrations up to $200 \mathrm{ng} / \mathrm{L}$ in the San Francisco Bay Delta (Schlenk et al., 2012), and also based on the European Union legislation for unregulated herbicides, such as diuron, which establishes $100 \mathrm{ng} / \mathrm{L}$ as the permissible limit for individual herbicides in drinking water (Sanchis-Mallols et al., 1998). All chemicals were dissolved in a sock solution of $1 \mathrm{~mL}$ of acetone and then added $(0.1 \mathrm{~mL})$ into the aquariums. Control groups also received the same volume of acetone to avoid ambiguous interpretation of the results due to possible solvent effects. Selection of the exposure period was based on previous studies with other species which showed reproductive effects after chronic exposure to diuron (Cardone et al., 2008; Fernandes et al., 2007). The concentration of $100 \mathrm{ng} / \mathrm{L}$ was chosen based on mean values found in contaminated aquatic environments (up to $160 \mathrm{ng} / \mathrm{L}$ ) (KöckSchulmeyera et al., 2013; Masiá et al., 2015).

\subsection{Chemical analyses}

Water samples $(10 \mathrm{~mL})$ from the experimental aquaria were taken before adding the fish into the aquaria at the beginning of exposures and prior to each renewal, for the measurement of diuron, DCPMU, DCPU and DCA concentrations by HPLC. The HPLC system (Shimadzu Corporation, Kyoto, Japan) consisted of one CBM20A communication bus module, two LC20AD-XR pumps, one DGU20A3R degassing unit, one SIL20AC-XR autosampler, one CTO20AR column oven, and one SPDM20A photodiodearray (PDA) detector. Fifty microliters of the water were filtered and directly injected into the system, and the compounds were separated by a Shimadzu Shim-Pack XR-ODS column $(2.0 \times 100.0 \mathrm{~mm}, 2.2 \mu \mathrm{m}$ particle size, $8 \mathrm{~nm}$ pore size). The PDA detector was set at $200-600 \mathrm{~nm}$ for all analytes, which were quantified at $250 \mathrm{~nm}$. The mobile phase consisted of acetonitrile and water $(40: 60, \mathrm{v} / \mathrm{v})$, and it was isocratically pumped in a flow rate of $0.5 \mathrm{~mL} / \mathrm{min}$. The column oven temperature was set to $40{ }^{\circ} \mathrm{C}$. Chromatogram was monitored during 5 min and peaks were identified and quantified using LAB Solutions 5.71 software (Shimadzu Corporation). The calculations 
were based on a calibration curve previously constructed by injecting authentic standards into the HPLC system (10-1000 ng/L). The minimum detection levels for all compounds was $10 \mathrm{ng} / \mathrm{L}$.

\subsection{Blood sampling and steroid assays}

At the end of the experimental period all animals were anesthetized with benzocaine $(9 \mathrm{mg} / \mathrm{L}$ ) for blood sampling. Blood was collected by puncturing the caudal vein with heparinized syringes (Liquemine, Roche, Rio de Janeiro, RJ, Brazil) and needles. Blood was centrifuged at $1300 \mathrm{~g}$ for $10 \mathrm{~min}$. The plasma was separated into aliquots and frozen at $-80^{\circ} \mathrm{C}$ for the subsequent $17 \beta$-estradiol $\left(\mathrm{E}_{2}\right)$ and $17 \alpha$-hydroxyprogesterone (17 $\alpha-\mathrm{OHP})$ assays. The plasma steroid level was measured by ELISA (Enzyme Linked Immunosorbent Assay) ( $E_{2}$ and $17 \alpha-O H P$ : Cayman Chemical, Michigan, USA). Plasma samples were run in duplicate with an acceptable limit of $\leq 20.0$ for the intra-assay coefficients of variation (Brown et al., 2004). Absorbance measurements were collected using a microplate reader (Victor 2, Perkin-Elmer, Waltham, MA, USA).

\subsection{Sample processing and histology}

After blood collection, fish were killed with a lethal dose of benzocaine $(28 \mathrm{mg} / \mathrm{L})$ and their gonads were collected. The ovary were removed and weighed to calculate the gonadosomatic indices (GSI), which is the percentage of total body weight represented by the ovary. For histological evaluation, ovarian samples (cranial, middle and caudal regions) were collected, fixed in Bouin solution as described by Pereira et al. (Pereira et al., 2013). The fixed material was embedded in Historesin (Historesin Plus, Leica, Heidelberg, Germany), cut into $2 \mu \mathrm{m}$ thick sections and stained with haematoxylin-fluoxin.

\subsection{Histomorphometric analyses}

Morphological analyses were performed on the ovary sections with ovarian lamellae that contained oocytes at various stages of development. Oocytes showing the nucleus in transversal sections were classified according to criteria given in Coward and Bromage (Coward and Bromage, 2005) and Pereira et al. (Pereira et al., 2013). The morphological changes were described using an Olympus BX41 microscope system (4x magnification) with an Olympus DP11 capture apparatus (with measurements performed using ImagePro Plus Version 4.1.0.0 software).

\subsection{Volume density of the gonads}

Volume density of the gonad was determined using light microscopy and a 320-intersection grid. Three fields from each region of ovary (cranial, middle, and caudal) ( 9 fields total) were randomly selected, giving a total of 2.880 points scored for each animal at $4 \mathrm{x}$ magnification. For this analysis, it was used the method applied by Pereira et al. (2013). Cells were classified as one of the following: pre-vitellogenic (PV), cortical alveoli (CA), early vitellogenic with incomplete vitellogenesis and cytoplasm not filled with yolk (EV), final vitellogenic with cytoplasm filled with yolk (FV), atretic (AT), and interstitial tissue (IT). Artifacts were rarely observed and were not considered in the total number of cells used to obtain the percentages.

\subsection{Statistical analysis}

Data normality was evaluated using the Cramer von - Mises test and Homoscedasticity with the Fmax test. The plasma steroid level, GSI and volume density were analyzed by comparing different treatments with a one-way analysis of variance (ANOVA). The Tukey test was used in post hoc analyses. A threshold of $P \leq 0.05$ was set to infer statistical significance. All statistical analyses were based on Zar (Zar, 1999).

\section{Results}

\subsection{Fish mortality, growth and exposure concentrations}

Mortality was not observed in any of the experimental groups. Differences were not observed in food intake or growth among treatments and controls $(P=0.35$, Table 1$)$. Measured values for diuron, DCA, DCPU and DCPMU in water are shown in Table 1.

\subsection{Steroid hormones and GSI}

Female Nile tilapia exposed to diuron metabolites for 25 days had significantly altered sex steroid levels (Fig. 1) and GSI (Fig. 2). There was an increase of approximately $20 \%$ in $E_{2}$ plasma levels $(\mathrm{P}=0.03$ ) of fish exposed to DCPMU, DCPU and DCA compared to the control and diuron treatments (Fig. 1. A). However, there was no significant difference in $17 \alpha-\mathrm{OHP}$ plasma levels $(\mathrm{P}=0.15)$ among experimental groups (Fig. 1. B). There was an increase of approximately $30 \%$ of the GSI $(P<0.0001)$ in animals exposed to diuron metabolites compared to the control and diuron treatments (Fig. 2).

\subsection{Histomorphometric analyses of the ovary}

Ovarian sections of control Nile tilapia demonstrated a normal distribution of ovarian lamellae, with the presence of the following oocyte types: PV, CA, EV, FV and TI (Fig. 3A). In all treatments the oocytes are presented as follows: PV (showed a large nucleus, centrally positioned with numerous nucleoli and cytoplasm intensely basophilic), CA (oocytes had a large nucleus, slightly stained with numerous nucleoli and the cytoplasm contained cortical alveoli), EV (oocytes the nucleus remained centrally positioned, had an irregular shape, and a large number of cortical alveoli vesicles were observed), FV (the nucleus remained centrally positioned, the predominance of cortical alveoli vesicles was no longer observed and oocytes were at their maximum size and were filled with protein yolk granules) and AT (atretic oocytes often had broken or absent nuclei, fragmentation of the zone radiata and irregular yolk distribution). However, examination of the ovarian lamellae morphometry of Nile tilapia exposed to diuron and its metabolites showed a significant decrease $(\sim 10 \%, \mathrm{P}<0.0001)$ in the percentage of primary ovarian follicles ( $\mathrm{PV}$ and $\mathrm{CA}$ oocytes) in comparison to the control group (Table 1 and Fig. 3B-C). Furthermore, exposure to diuron metabolites caused a decrease $(\sim 9 \%$, $\mathrm{P}=0.0002$ ) in the percentage of EV oocytes in comparison to the control group (Table 2). On the other hand, following treatment with diuron metabolites, there was an increase of approximately $30 \%$ in FV oocytes $(\mathrm{P}<0.0001)$ and $10 \%$ in AT oocytes $(\mathrm{P}=0.0073)$. In particular, the greatest values were observed in animals exposed to DCPMU and DCA metabolites (Table 1 and Fig. 3 C $-D$ ). It is important to note that we did not observe changes in the morphological composition of PV, CA, EV, FV and AT oocytes between treatments, only variations in quantitative percentage of these oocytes.

\section{Discussion}

The results support our predictions that long term exposure to diuron and its metabolites caused alterations in plasma steroids and gonadal histology in adult females of Nile tilapia consistent with estrogenic activity. Diuron metabolites accelerated the 
Table 1

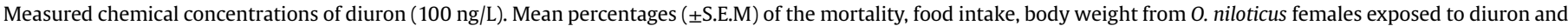
its metabolites during 25 days. (ANOVA, Tukey test, $\mathrm{P}<0.05$ ).

\begin{tabular}{|c|c|c|c|c|c|}
\hline \multirow[t]{2}{*}{ Parameters } & \multicolumn{5}{|l|}{ Treatments } \\
\hline & Control & Diuron & DCA & DCPU & DCPMU \\
\hline Mortality (\%) & 0 & 0 & 0 & 0 & 0 \\
\hline Food intake $(\mathrm{g})$ & $10.84 \pm 0.32$ & $11.01 \pm 0.23$ & $10.55 \pm 0.22$ & $10.88 \pm 0.17$ & $10.79 \pm 0.12$ \\
\hline Body weigth (g) & $70.96 \pm 2.07$ & $68.76 \pm 1.96$ & $71.68 \pm 1.04$ & $74.99 \pm 0.57$ & $69.38 \pm 2.69$ \\
\hline Measured conc. (ng/L) & $<10$ & $67.9 \pm 29.7$ & $61.67 \pm 16.2$ & $53.4 \pm 6.9$ & $53.5 \pm 0.7$ \\
\hline
\end{tabular}
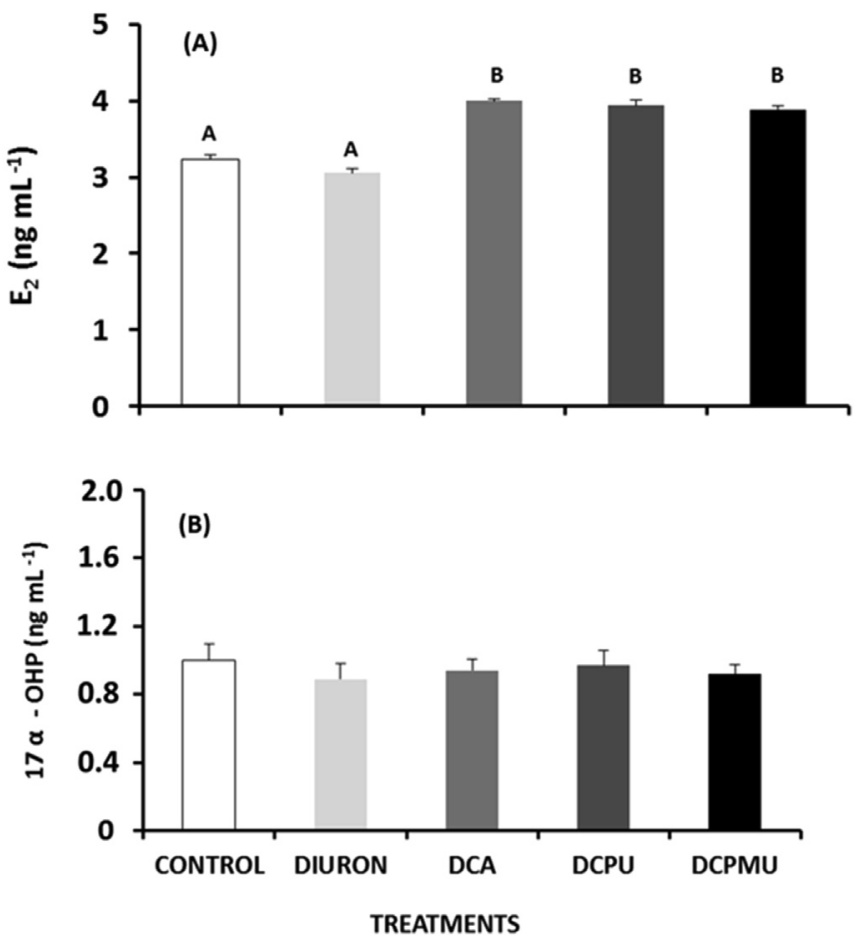

Fig. 1. (A) Mean ( \pm S.E.M) plasma concentrations of $E_{2}$ in $O$. niloticus females exposed to $100 \mathrm{ng} / \mathrm{L}$ diuron and its metabolites during 25 days. Different letters indicate significant differences among treatments (ANOVA, Tukey test, $\mathrm{P}<0.05)$. (B) Mean $( \pm$ S.E.M) plasma concentrations of $17 \alpha-\mathrm{OHP}$ in 0 . niloticus females exposed to diuron and its metabolites during 25 days.

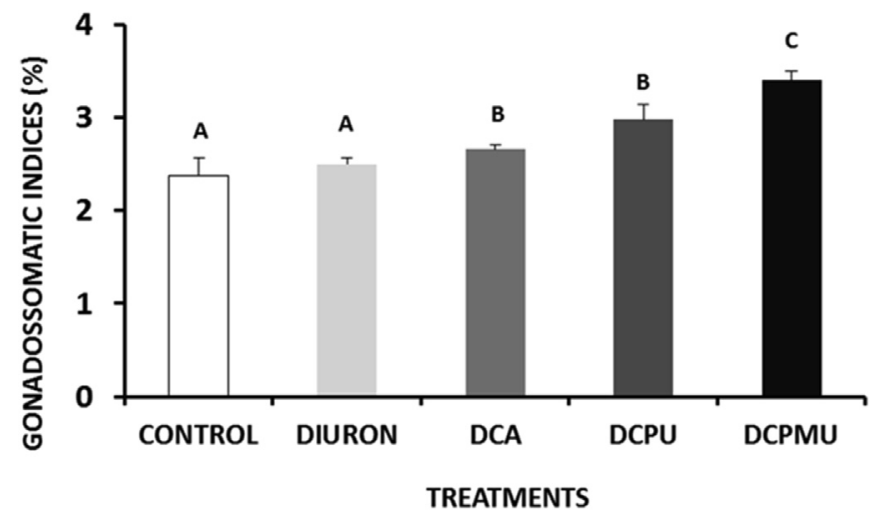

Fig. 2. Mean percentages $( \pm$ S.E.M) of the gonadosomatic indices in 0 . niloticus females exposed to $100 \mathrm{ng} / \mathrm{L}$ diuron and its metabolites during 25 days. The diferente letters indicate significant differences among treatments. (ANOVA, Tukey test, $\mathrm{P}<0.05$ ).

oogenesis of Nile tilapia females causing increased gonadosomatic indices, and elevations in plasma concentration of the sex steroid $\mathrm{E}_{2}$ and in the percentage of final vitellogenic oocytes.
In teleost fish, sex steroids are responsible for regulating gametogenesis (Nagahama and Yamashita, 2008; Haider, 2007; Lubzens et al., 2010). The primary role of $E_{2}$ is the stimulation of hepatically-derived vitellogenin (yolk protein) production, which is then incorporated into developing ovarian follicles (Nagahama and Yamashita, 2008; Lubzens et al., 2010). In this study, we observed that the exposure of female Nile tilapia to diuron metabolites significantly increased $E_{2}$ plasma levels, showing potential disruption of estrogen biosynthesis or clearance. Previous studies using in vivo bioassay guided fractionation in water extracts from the Central Valley and San Francisco Bay Delta in California (USA) indicated diuron in fractions with in vivo estrogenic activity, but not in vitro activity (Schlenk et al., 2012). As an individual compound, diuron failed to induce vitellogenin in male Japanese medaka (Oryzias latipes), but when the compound was combined with bifenthrin, several alkylphenol ethoxylates and alkylphenols at environmentally measured concentrations, vitellogenin expresssion was observed (Schlenk et al., 2012). EDCs can cause estrogenic activity through a number of mechanisms including direct interactions with specific nuclear or membrane receptors in target cells or indirectly by affecting synthesis and clearance of sex steroid hormones (Kroon et al., 2014; Sun et al., 2014). Bauer et al. (Bauer et al., 1998) showed that diuron and some of its metabolites antagonized androgen receptors and altered the synthesis, secretion, and/or metabolism of testosterone. The relationship between testosterone and $\mathrm{E}_{2}$ is unclear, but reductions in testosterone may have feedback loop impacts on $\mathrm{E}_{2}$ biosynthesis (Nagahama and Yamashita, 2008; Lubzens et al., 2010). Additional studies are needed to confirm this hypothesis.

Augmented $\mathrm{E}_{2}$ can increase hepatically-derived vitellogenin production and/or incorporation into developing oocytes (Nagahama and Yamashita, 2008; Lubzens et al., 2010). The vitellogenic oocytes (characterized by the deposition in the cytoplasm exogenous yolk) significantly increased in size due to the occurrence of vitellogenin (Lubzens et al., 2010). Thus, the increase in the circulating $\mathrm{E}_{2}$ after treatment with diuron and its metabolites might be causing an excessive release of hepatic vitellogenin and consequently promoting an increased GSI and in the percentage in final vitellogenic oocytes in the animals exposed to diuron metabolites. Furthermore, the greater percentage of vitellogenic follicles indicates that diuron metabolites may intensify and accelerate the follicle maturation process eventually damaging oogenesis. In contrast diuron and metabolites had no effect on the $17 \alpha-\mathrm{OHP}$ activity in fish ovaries. The steroid $17 \alpha$-OHP is the main precursor of $17 \alpha, 20 \beta$-dihydroxy-4-prengnen-3-one (DHP), which is the most potent hormone inducing ovulation in fish (Nagahama and Yamashita, 2008). Failure to alter biosynthesis of DHP suggests a target for diuron or its metabolites down-stream of $17 \alpha-17 \alpha-\mathrm{OHP}$ such as 17 Hydroxysteroid dehydrogenase or $5 \alpha$-reductase. Further study evaluating the expression and/or activity of these enzymes is warranted.

In conclusion, the results of this study reveal significant estrogenic activity caused by diuron herbicide metabolites in teleost oogenesis. These compounds are capable of increasing $E_{2}$ plasma 

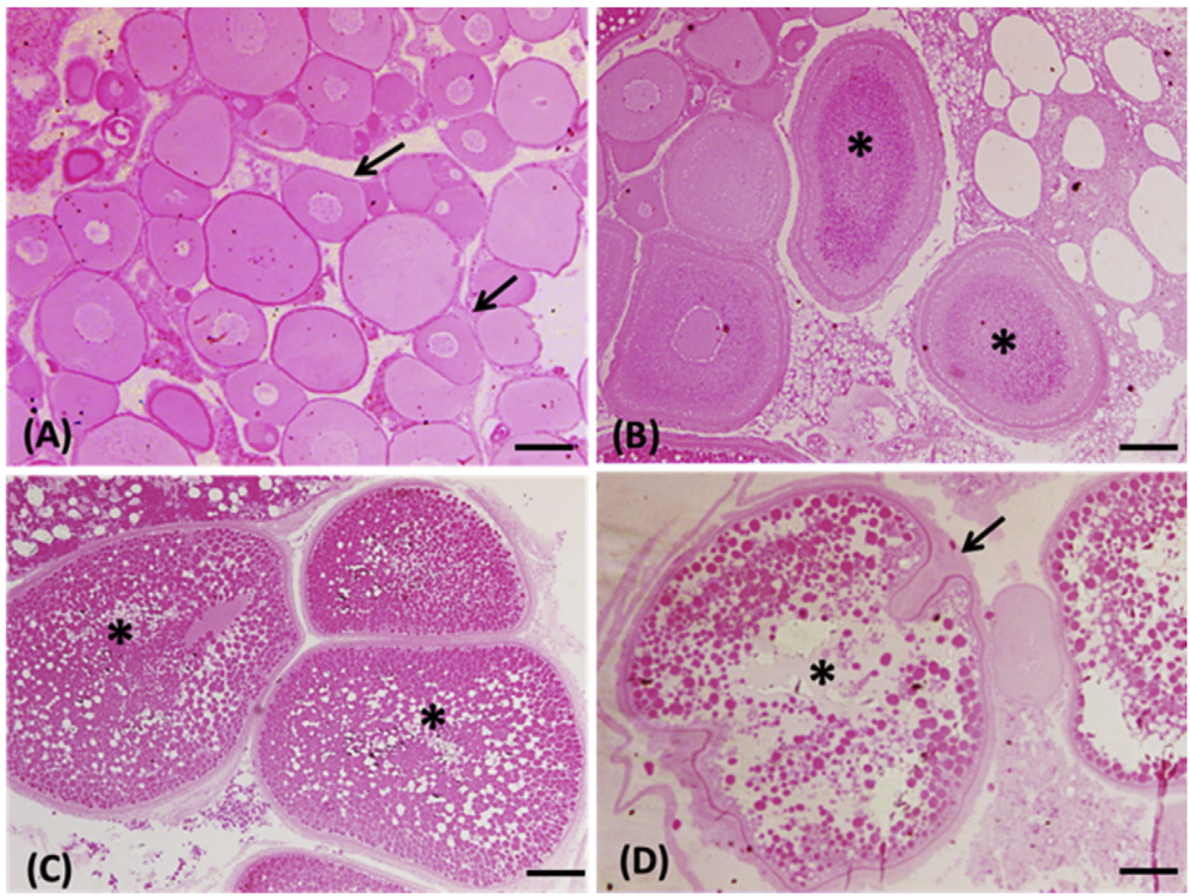

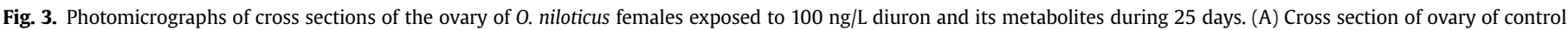

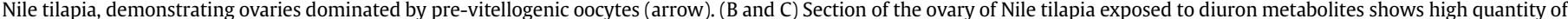

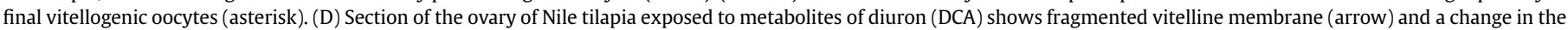
appearance of the cytoplasm (asterisk). Hematoxylin-floxin. Scale bar $=100 \mu \mathrm{M}$.

\section{Table 2}

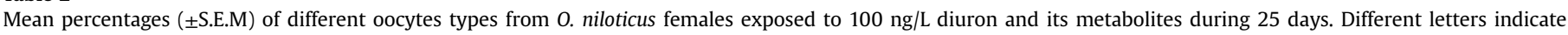
significant differences among treatments. (ANOVA, Tukey test, $\mathrm{P}<0.05$ ).

\begin{tabular}{|c|c|c|c|c|c|}
\hline \multirow[t]{2}{*}{ Germ and somatic cells } & \multicolumn{5}{|l|}{ Treatments } \\
\hline & Control (\%) & Diuron (\%) & DCA (\%) & DCPU (\%) & DCPMU (\%) \\
\hline Previtellogenic & $13.23 \pm 0.40^{\mathrm{a}}$ & $2.94 \pm 0.38^{\mathrm{b}}$ & $1.02 \pm 0.19^{\mathrm{b}}$ & $0.78 \pm 0.18^{b}$ & $0.34 \pm 0.16^{b}$ \\
\hline Cortical alveoli & $4.08 \pm 0.28^{\mathrm{a}}$ & $1.03 \pm 0.22^{\mathrm{b}}$ & $0.86 \pm 0.16^{\mathrm{b}}$ & $0.58 \pm 0.15^{\mathrm{b}}$ & $0.45 \pm 0.18^{b}$ \\
\hline Early vitellogenic & $10.43 \pm 0.43^{\mathrm{a}}$ & $8.79 \pm 0.48^{\mathrm{a}}$ & $2.05 \pm 0.31^{\mathrm{b}}$ & $1.27 \pm 0.25^{\mathrm{b}}$ & $1.40 \pm 0.23^{b}$ \\
\hline Final vitellogenic & $53.12 \pm 0.56^{\mathrm{b}}$ & $55.77 \pm 0.59^{b}$ & $79.42 \pm 1.55^{\mathrm{a}}$ & $83.55 \pm 0.45^{\mathrm{a}}$ & $85.89 \pm 0.44^{\mathrm{a}}$ \\
\hline Atretic & $0.25 \pm 0.13^{b}$ & $0.54 \pm 0.22^{\mathrm{b}}$ & $9.36 \pm 0.60^{\mathrm{a}}$ & $1.87 \pm 0.28^{\mathrm{b}}$ & $1.62 \pm 0.27^{\mathrm{b}}$ \\
\hline Interstitial tissue & $12.13 \pm 0.30^{\mathrm{a}}$ & $10.29 \pm 0.41^{\mathrm{a}}$ & $10.40 \pm 0.34^{\mathrm{a}}$ & $10.93 \pm 0.35^{a}$ & $10.26 \pm 0.30^{\mathrm{a}}$ \\
\hline
\end{tabular}

levels and quantity of vitellogenic oocytes causing enhanced ovarian development of $O$. niloticus females. In order to determine potential impacts of fishery reproduction and populations, further experiments are needed to evaluate the hatch and viability of the gametes from spawning animals and steroid biosynthesis following long term exposure to diuron and its metabolites.

\section{Acknowledgements}

The authors would like to acknowledge the "Programa RecémDoutor"-PROPe- UNESP for Scholarship. This work has the financial support of FAPESP-BIOEN Program (2011/52061-8) and CNPq (401884/2012-0). EAA is a recipient of a CNPq productivity fellowship (307603/2014-8). The authors disclose any potential sources of conflict of interest.

\section{References}

Abbas, K., Reponen, P., Turpeinen, M., Jalonen, J., Pelkonen, O., 2007. Characterization of diuron $\mathrm{N}$-demethylation by mammalian hepatic microsomes and cDNA expressed human cytochrome P450 enzymes. Drug Metab. Disp. 35 $1634-1641$

Bauer, E.R., Meyer, H.H., Stahlschmidt-Allner, P., Sauerwein, H., 1998. Application of an androgen receptor assay for the characterisation of the androgenic or antiandrogenic activity of various phenylurea herbicides and their derivatives. Analyst 123, 2485-2487.

Brown, J., Walker, S.E., Steinmain, K., 2004. Endocrine Manual for the Reproductive Assessment of Domestic and Non-domestics Species. Conservation and Research Center, Smithsoniańs National Zoological Park, Front Royal, Virginia EUA, p. 93.

Cardone, A., Comitato, R., Angelini, F., 2008. Spermatogenesis, epididymus morphology and plasma sex secretion in the male lizard Podarcis sicula exposed to diuron. Environ. Res. 108, 214-223.

Coward, K., Bromage, N.R., 2005. Histological classification of oocyte growth and the dynamics of ovarian recrudescence in Tilapia zillii. J. Fish. Biol. 53, 285-302.

Da Rocha, M.S., Arnolda, L.L., Dodmanea, P.R., Penningtona, K.L., Qiua, F., De Camargo, J.L.V., Cohena, S.M., 2013. Diuron metabolites and urothelial cytotoxicity: In vivo, in vitro and molecular approaches. Toxicology 314, 238-246.

Fernandes, G.S.A., Arena, A.C., Fernandez, C.D., Mercadante, A., Barbisan, L., Kempinas, W.G., 2007. Reproductive effects in male rats exposed to diuron. Reprod. Toxicol. 23, 106-112.

Forsgren, K.L., Qu, S., Lavado, R., Cwiertny, D., Schlenk, D., 2014. Trenbolone acetate metabolites promote ovarian growth and development in adult Japanese medaka (Oryzias latipes). Gen. Comp. Endocr. 202, 1-7.

Gagnon, M.M., Rawson, C.A. 2009. Diuron increases spinal deformity in early-lifestage pink snapper Pagrus auratus. Mar. Pollut. Bull. 58, 1083-1085.

Giacomazzi, S., Cochet, N., 2004. Environmental impact of diuron transformation: a review. Chemosphere 56, 1021-1032.

Gooddy, D.C., Chilton, P.J., Harrison, I., 2002. A field study to assess the degradation and transport of diuron and its metabolites in a calcareous soil. Sci. Total Environ. 297, 67-83. 
Haider, S.G., 2007. Leydig cell steroidogenesis: Unmasking the functional importance of mitochondria. Endocrinology 148, 2581-2582.

Hodge, H.C., Boyce, A.M., Deichmann, W.B., Kraybill, H.F., 1967. Toxicology and noeffect levels of aldrin and dieldrin. Toxicol. Appl. Pharmacol. 10, 613-675.

Köck-Schulmeyera, M., Villagrasa, M., Alda, M.L., Céspedes-Sánchez, R., Frances Ventura, F., Barcelóa, D., 2013. Occurrence and behavior of pesticides in wastewater treatment plants and their environmental impact. Sci. Total Environ. 458, 466-476.

Kroon, F.J., Hook, S.E., Jones, D., Metcalfe, S., Hannah, L.O., 2014. Effects of atrazine on endocrinology and physiology in juvenile barramundi, Lates calcarifer (Bloch). Environ. Toxicol. Chem. 33 (7), 1607-1614.

Kroon, F.J., Hook, S.E., Metcalfe, S., Jones, D., 2015. Altered levels of endocrine biomarkers in juvenile barramundi (Lates calcarifer; Bloch) following exposure to commercial herbicide and surfactant formulations. Environ. Toxicol. Chem. 34 (8), 1881-1890.

Lamoree, M.H., Swart, C.P., Van der Horst, A., Van Hattum, B., 2002. Determination of diuron and the antifouling paint biocide irgarol 1051 in Dutch marinas and coastal Waters. J. Chromatogr. A 970, 183-190.

Lubzens, E., Young, G., Bobe, J., Cerda, J., 2010. Oogenesis in teleosts: how fish eggs are formed. Gen. Comp. Endocrinol. 165, 367-389.

Masiá, A., Campo, J., Navarro-Ortega, A., Barceló, D., Picó, Y., 2015. Pesticide monitoring in the basin of Llobregat River (Catalonia, Spain) and comparison with historical data. Sci. Total Environ. 503, 68-78.

Mhadhbi, L., Beiras, R., 2012. Acute toxicity of Seven selected pesticides (Alachlor, atrazine, dieldrin, diuron, Pirimiphos-Methyl, Chlorpyrifos, diazinon) to the Marine fish (Turbot, Psetta maxima). Water Air Soil Pollut. 223, 5917-5930.

Miranda, A.L., Roche, H., Randi, M.A.F., Menezes, M.L., Oliveira, C.A., 2008. Bioaccumulation of chlorinated pesticides and PCBs in the tropical freshwater fish Hoplias malabaricus: histopathological, physiological, and immunological findings. Environ. Int. 34, 939-949.

Nagahama, Y., Yamashita, M., 2008. Regulation of oocyte maturation in fish. Dev. Growth Differ. 50, 195-221.

Nebeker, A.V., Schuytema, G.S., 1998. Chronic effects of the herbicide diuron on freshwater cladocerans, amphipods, midges, minnows, worms, and snails. Arch. Environ. Con Tox. 35, 441-446.

Pereira, T.S.B., Moreira, R.G., Batlouni, S.R., 2013. Dynamics of ovarian maturation during the reproductive cycle of Metynnis maculatus, a reservoir invasive fish species (Teleostei: Characiformes). Neotrop Ichthyol. 11 (4), 821-830.

Pereira, T.S.B., Boscolo, C.N.P., Silva, D.G.H., Batlouni, S.R., Schlenk, D., Almeida, E.D.,
2015. Anti-androgenic activities of diuron and its metabolites in male Nile tilapia (Oreochromis niloticus). Aquat. Toxicol. 164, 10-15.

Saglio, P., Trijasse, S., 1998. Behavioral responses to atrazine and diuron in goldfish. Arch. Environ. Con Tox. 35, 484-491.

Sanchez-Muros, M.J., Villacreces, S., Lama, G.N., Haro, C., Garcia-Barroso, F., 2013. Effects of chemical and handling exposure on fatty acids, oxidative stress and morphological welfare indicators in gilt-head sea bream (Sparus aurata). Fish. Physiol. Biochem. 39, 581-591.

Sanchis-Mallols, J.M. Sagrado, S., Medina-Hernandez, M.J. Camanas, R.M.V., BonetDomingo, E., 1998. Determination of phenylurea herbicides in drinking water by HPLC and solid-phase extraction. J. Liq. Chromatogr. Relat. Technol. 21, 869-881.

Sanderson, T., Van den Berg, M., 2003. Interactions of xenobiotics with the steroid hormone biosynthesis pathway. Pure Appl. Chem. 75 (11-12), 1957-1971.

Scheil, V., Kienle, C., Osterauer, R., Gerhardt, A., Kohler, H.R., 2009. Effects of 3,4dichloroaniline and diazinon on different biological organisation levelsof zebrafish (Danio rerio) embryos and larvae. Ecotoxicology 18, 355-363.

Schlenk, D., Lavado, R., Loyo-Rosales, J., Jones, W., Maryoung, L., Riar, N., Werner, I., Sedlak, D., 2012. Reconstitution studies of pesticides and surfactants exploring the cause of estrogenic activity observed in surface waters of the San Francisco Bay Delta. Environ. Sci. Technol. 46, 9106-9111.

Simpson, E.R., Clyne, C., Rubin, G., Boon, W.C., Robertson, K., Britt, K., Speed, C., Jones, M., 2002. Aromatase - a brief overview. Annu. Rev. Physiol. 64, 93-127.

Sumpter, J.P., Jobling, S., 1995. Vitellogenesis as a biomarker for estrogenic contamination of the aquatic environment. Environ. Health Perspect. 103 (7), $173-178$.

Sun, L., Jin, R., Peng, Z., Zhou, Q., Qian, H., Fu, Z., 2014. Effects of trilostane and fipronil on the reproductive axis in an early life stage of the Japanese medaka (Oryzias latipes). Ecotoxicology 23, 1044-1054.

Tabb, M.M., Blumberg, B., 2006. New modes of Action for endocrine-disrupting chemicals. Mol. Endocrinol. 20 (3), 475-482.

Tixier, C., Sancelme, M., Ait-Aissa, S., Widehem, P., Bonnemoy, F., Cuer, A. Truffaut, N., Veschambre, H., 2002. Biotransformation of phenylurea herbicides by a soil bacterial strain, Arthrobacter sp. N2: structure, ecotoxicity and fate of diuron metabolite with soil fungi. Chemosphere 46, 519-526.

Vinggaard, A.M., Hnida, C., Breinholt, V., Larsen, J.C., 2000. Screening of selected pesticides for inhibition of CYP19 aromatase activity in vitro. Toxicol Vitro. 14, 227-234.

Zar, J., 1999. Biostatistical Analyses. Prentice Hall, New Jersey. 